\title{
Research of Confucianism in American Chinese Literature
}

\author{
Sun Nannan \\ School of Foreign Languages, Baicheng Normal University
}

\begin{abstract}
:
As one of the traditional Chinese cultures, the Confucian literary thought is the collision and fusion of the Chinese and American cultures in the American Chinese literature, forming the literary works with distinct colors. This literary style is formed mainly due to the era and their life experiences of the American Chinese writers. They illustrate the structure and form of the Confucian ideology from a brand-new perspective, leading to a cross-cultural phenomenon of the works of overseas Chinese writers in terms of language and culture. This article will discuss the embodiment of Confucianism in American Chinese literature according to the American Chinese literature of different periods and the social and cultural context at that time.
\end{abstract}

Key Words: American Chinese literature; Confucianism

\section{Introduction}

In Inside the Chinese American Literature, Professor Zhang Longhai explores the development process of American Chinese literature, discloses that American Chinese literature gradually changes from marginalization to centralization and that in various literature theories, the overseas Chinese writers inject their thinking of the social and contemporary issues to the works, thus subverting the mainstream hegemony discourse, remodeling the American Chinese culture and history and showing the ethnic voice through his own works. Professor Zhang Longhai regards this piece of works as the starting point of research of American Chinese literature, analyzes the changes and characteristics of overseas Chinese literature under different historical areas through multiple times, provides the brand-new panorama of American Chinese literature for our country to study the 
Confucianism in American Chinese literature and boosts it to own more profound academic research value and realistic significance.

\section{Main Embodiment of Confucianism in American Chinese Literature}

The study of Confucianism in American Chinese literature not only helps us to explore the development of our native culture in the context of globalization, but also is of profound value and significance to make Chinese culture turn to modern culture, pursue the cultural diversity and national cultural status in the process of our country's pursuing the global cultural and political differences. Secondly, the study of Confucian culture in Chinese literature will help us to examine Chinese traditional culture from the perspective of others, and help us to carry forward the fine traditional cultures and promote the development of social civilization.

The thoughts of "benevolence", "righteousness", "rituality", "wisdom", "faith", "tolerance", "loyalty", "filial piety" are the core of Confucianism in traditional Chinese cultures. Among them, "filial piety" is the one that is most embodied in American Chinese literature. First of all, "filial piety" in the feudal society in China is mainly embodied in patriarchal hierarchy or family economic relations. However, in the American Chinese literature, it is reflected in the American dream, family values, marriage and sexual orientation and other aspects. Through the conflict of "filial piety" in Chinese and American culture, it shows that its meaning is inseparable from the hierarchical and social characteristics of its time. Secondly, in the American Chinese literature, Confucianism is mainly expressed in the narration of "speech". Through analysis of "silence", "lie" and "secret" in American Chinese literature works, we can see that the language expression modes in the works actually reflect the race and humanity political appearance of the American society. Finally, the study of Confucianism in American Chinese literature can help us to analyze the origins and development of ethnic minorities. By interpreting the relations between the social systems such as political awareness and racism for the formation of ethnic minorities and Confucianism, it discloses the real scene that the masses become ethnic minorities under the background of model ethnic minorities.

\section{Confucianism in the American Chinese Literature in Different Periods}

According to critics' criticism of American Chinese literature, we can roughly divide the Chinese American literature history into three stages: the 70s in the germination stage, the 1980 s to 1990 s in the developing stage, the post-1990s in the diversified stage.

From the 1970s to the early 1980s, Confucianism in Racist Love, the American Chinese literature works attracted attention from the literature circle, who began to pay attention to American Chinese literature. Then in 1982, the publication of Introduction to American Asian Literature Works and The Social Background 
boosted the American Chinese literature to formally enter the literary and academic field of criticism. This period was precisely the stage of discrimination against races in the United States, where English-speaking Caucasians dominated the United States, leaving ethnic minorities on the margins of the society for a long time, along with cultural and socio-economic marginalization. In the early days of the 20th century, the first American novelist with Chinese descent, Edith Eaton, described the complex social status of Chinese-Americans with literature, which was as a new starting point for Chinese literature in American literature. In the 1970s, with the constant efforts made by the Asian groups such as Zhao Jianxiu and Chen Yaoguang (writer of Racist Love), the American Chinese literature that was at the downward state gained long-term development. The most representative works Hey! Works Collection of American Asian Writers shows the common particularity of the Chinese writers and their works, which is the nature of the ethnic people in the then social system. The rich emotions of writers in the literature works became the standards to judge the realness of the Chinese writers and also boosted the status construction of American Chinese literature to be realized.

Zhao Jianxiu created Chickencoop Chinaman, which is the first drama that enters the American mainstream theater and the first drama written by American Chinese in history. Zhao Jianxiu has arranged the Chinese events in the plot in a unique writing method in his works for multiple times. For example, in the novel Tang Laoya, he cites the proud history of Chinese road repair. Gayatric C. Spivak, the top cultural critic, holds that Tang Laoya is a piece of works that makes people have query about racial discrimination, which more shows the illustration of the cultural hegemony structure of the empire. In the passage that "the spring festival is coming, the history teachers in the Tang Laoya School teaches the Chinese culture the the students". In the paper, the history teacher explains the reason for the passiveness and negativeness of Chinese like this: "the American Chinese have been influenced by the long-term Confucianism and the mysticism of the Chan. Until the mid of the 20th century, the passive Chinese have been suppressed by the Americans, but we can do nothing." It is safe to say that the viewpoint held by the history teacher to the Chinese actually represents that of the entire American society. In addition, at the end of Tang Laoya, Zhao Jiexiu makes use of the act that the hero Weng fires the flight lamp to sacrifice the ancestors of Chinese to show the importance of finding the national cultural features and their strength source to the overseas Chinese group.

The early 1980 s to the mid-1990s is the mid-stage of the development of American Chinese literature. In this stage, with the publication of Among World: Chinese Female Writers, a piece of works specially targeted at the Chinese female writers, critics in the criticism field turn the focus of Chinese literature criticism from writers' identity and social background to the analysis of literary texts in order to combine the status differences of overseas Chinese caused by gender, thus laying a foundation for the literary criticism in the Chinese literary works. At the same time, the Chinese American scholar Ling Jinqi mentions in Narration of Nationalism that we should recombine the attention of "awareness form" and "shape form" from multiple negotiation perspectives and conduct 
structural analysis of Confucianism in the Chinese works from multiple perspectives.

In 1987, Amy Tan created the novel Joy Luck Club according to her grandmother's and her mother's experience. In the novel, the relationship between mothers and daughters in four groups of families was described as "clue" throughout the emotional intertwining between mothers and daughters in time and space, so that Confucianism hidden in the language of literature was communicated to the world through everyday life in the context of American social and cultural politics at that time. For example, the idea of male superiority and female inferiority was deeply felt in the female groups. In Joy Luck Club, the daughters receive the American education since the childhood and their ideology and behavior modes have formed the American-style concepts; Lina, as the only one who firmly believe that marriage can achieve equality between men and women suffers from severe wound in her dreamy marriage life under the blow of her economic and social status. In addition, in Joy Luck Club, the "obligation-based" idea of Confucianism culture inherited by the mothers is built to be the supreme family concept; through cultural conflicts between mothers and daughters, the idea of respecting the elderly in Confucianism is mainly embodied.

Since the late 1990s, the development of American Chinese literature has diversified phenomenon. On the one hand, influenced by the foreign countries that bring the postmodern theory to literary research, it makes the literary criticism go beyond not only the limitation of gender, but also the limitation of nations. On the other hand, domestic researches of American Chinese literature have gradually taken on the prosperous tendency. During this period, American Chinese literature has formed a "cross-border" trend of development; the new-generation writers such as Ren Bilian try to transcend their identity of their ethnic groups and make them no longer be confused about whether to be American or Chinese. Such conception immediately gains the response of more people. In the current globalized age, the frequent migration among races makes the bound of cultural status value. But in the same period, Chinese writers still have some people who persist in the writing of Chinese traditional life, the most representative of which is Chinatown.

For example, in the novel Bone by Wu Huiming, it gives a detailed illustration of the characters in the story who choose to escape from the lifestyle of Chinatown in face of the life in Chinatown. The loneliness and helplessness of Anna's spirituality reminds the Chinese people of their confusion of identity. Nina's "flight" proclaims the desire of the Chinese people to get rid of the bondage of Chinatown, and finally recalls the memory of Chinatown. Finally, it uses Lyra's memories of Chinatown to teach the Chinese descendants how to treat Chinatown correctly. Through the novel Bone, Wu Hming discloses to the world that Chinatown, as any origin place for the overseas Chinese, not only has the hope for life, but also is a spiritual comfort.

\section{Conclusion:}

The traditional Chinese Confucianism has gained constant development in 
American Chinese works in terms of the social system, political outlook and growth of writers in different periods in the American Chinese literature. In the way of gradually adapting to the western cultures, the works spread the Confucianism in the Chinese literature in different forms, thus making it own more far-reaching value in the literature research.

\section{References:}

[1] Wang Yuming. Memetics Analysis of Confucianism Culture in Works of Amy Tan, Huang Yuxue, Tang Tingting [J] Journal of Chifeng University (edition of philosophy and social science), 2015, 36

[2] Ou Yan. Research of Confucianism in American Chinese Literature [J] North Literature (midmonth journal), 2016, (9)

[3] Li Ying. On Translation and Reception of the Analects of Confucius in Britain and America [D]; Sichuan University, 2002 